\title{
Consumption of plant sterols in Belgium: consumption patterns of plant sterol-enriched foods in Flanders, Belgium
}

\author{
Isabelle Sioen $^{1 *}$, Christophe Matthys ${ }^{1}$, Inge Huybrechts ${ }^{1}$, John Van Camp ${ }^{2}$ and Stefaan De Henauw ${ }^{1,3}$ \\ ${ }^{1}$ Department of Public Health, Faculty of Medicine and Health Sciences, Ghent University, UZ-2 Blok A, De Pintelaan 185, \\ B-9000 Ghent, Belgium \\ ${ }^{2}$ Department of Food Safety and Food Quality, Ghent University, Coupure Links 653, B-9000 Ghent, Belgium \\ ${ }^{3}$ Department of Nutrition and Dietetics, Faculty of Health Care, University College Ghent, Keramiekstraat 80, B-9000 Ghent, \\ Belgium
}

(Received 26 January 2010 - Revised 20 September 2010 - Accepted 27 September 2010 - First published online 27 January 2011)

\section{Abstract}

The present study describes the consumption of foods enriched with plant sterols (PS) and supplements containing PS, and evaluates PS intakes via the current consumption and for specific consumption scenarios. A market inventory was performed to collate different PSenriched food items and supplements available in Belgium. An FFQ was developed to investigate the consumption of PS-enriched foods and supplements. A total of 139 pre-school children (2.5-7 years old) and 569 adults (308 women and 261 men) living in Flanders (the northern, Dutch-speaking part of Belgium) participated in the study. Of these, $21 \%$ (Flemish pre-school children) and $28 \cdot 5 \%$ (Flemish adults) consume PS-enriched food products, leading to a mean PS intake in the consumer group of $0 \cdot 70$ (SD 0.61 ) g/d for pre-school children and 1.51 (SD 1.42) g/d for adults. Of the adult PS consumers, $23.2 \%$ did not suffer from elevated blood cholesterol levels; $50 \%$ of them had a PS intake less than or equal to $1 \mathrm{~g} / \mathrm{d}$ and $16.4 \% \mathrm{had}$ a PS intake above $3 \mathrm{~g} / \mathrm{d}$ and $7 \cdot 8 \%$ even had an intake above $4 \mathrm{~g} / \mathrm{d}$. Scenario studies assessed the intake when all Belgian adults would consume PS-enriched margarines without (scenario 1) or with (scenario 2) a daily consumption of a PS-enriched yoghurt drink. This resulted in an intake above $3 \mathrm{~g} / \mathrm{d}$ in $17 \%$ (women) and $29 \%$ (men) for scenario 1 and $40 \%$ (women) and 53\% (men) for scenario 2. The results indicate that PS-enriched food products are also consumed by the non-target group. Efficient communication tools are needed to inform consumers better about the target group of PS-enriched products, the advised dose per day and alternative dietary strategies to lower the blood cholesterol level.

Key words: Plant sterols: Enriched foods: Dietary intake

Already back in the 1950s, the cholesterol-lowering effect of phytosterols, phytosterol esters, phytostanols and/or phytostanol esters - in the present study referred to by the term 'plant sterols (PS)' - was described ${ }^{(1)}$. Based on this health beneficial characteristic, food industries started to add PS to food products ${ }^{(2)}$. These food products were meant to help people with increased cholesterol level by a diet-based approach. Based on scientific evidence, it is generally accepted that the consumption of $1-3 \mathrm{~g} / \mathrm{d}$ lowers blood LDL-cholesterol by $5-15 \%$, without having a negative effect on HDL-cholesterol level. Furthermore, it is proven that an intake above $3 \mathrm{~g} / \mathrm{d}$ has no additional effect ${ }^{(1-4)}$.

PS are bioactive compounds of which little is known about the effect of long-term intake of amounts higher than the normal consumption level. Due to its limited absorption in the human body, PS show no systematic toxicity effects, i.e. no endocrine, teratogenic, mutagenic or carcinogenic effects ${ }^{(3,5)}$. However, PS interfere with the absorption of carotenoids. In contrast, they have no effect on plasma levels of fat-soluble vitamins, such as vitamins $\mathrm{A}, \mathrm{D}, \mathrm{E}$ and tocopherols ${ }^{(5)}$. $\beta$-Carotene is an important precursor of vitamin A. Research in The Netherlands has indicated that consumption of $3 \mathrm{~g} \mathrm{PS} / \mathrm{d}$ in 1 year leads to a decrease of $33 \%$ in $\beta$-carotene blood levels. However, $\beta$-carotene has not been deduced as giving serious cause for concern except in cases where vitamin A requirement is higher than normal, as in pregnancy, lactation or infancy. In all circumstances, it remains important to consume enough fruits and vegetables when using PS-enriched foods ${ }^{(5)}$. Given these facts, the European Food Safety Authority reported, as a prudent precaution,

Abbreviation: PS, plant sterols.

*Corresponding author: I. Sioen, fax +329332 49 94, email isabelle.sioen@ugent.be 
that intakes of PS should not exceed $3 \mathrm{~g} / \mathrm{d}^{(2)}$. A few studies about the consumption of PS-enriched food items are already available $e^{(2,6-8)}$. However, information about the Belgian situation is lacking.

Foods enriched with PS are novel ones that cannot be placed on the European market without the permission of the European Commission. Moreover, the necessary labelling of foods and food ingredients with added PS is described in detail in the Commission Regulation (European Commission) no. 608/2004. Some aspects of this regulation are as follows: 'there shall be a statement that the product is intended exclusively for people who want to lower their blood cholesterol level'; 'there shall be an easily visible and legible statement that the product may not be nutritionally appropriate for pregnant and breast-feeding women and children under the age of 5'; 'there shall be a statement that the consumption of more than $3 \mathrm{~g} / \mathrm{d}$ of added PS should be avoided'. The PS-enriched products that are put on the Belgian market need to follow the European regulation.

One part of the Belgian PHYTOST-project (enrolled from June 2008 to May 2009) included (1) collection of data about the consumption of novel foods enriched with PS and/or supplements containing PS and (2) evaluation of PS intakes via these enriched foods based on the present consumption pattern and on consumption scenarios. This was done in two subgroups of the Belgian population: pre-school children and adults. Both objectives were together needed for a good risk assessment study.

The results of the project are described in two different papers, since the methodology and the data used and collected for the two objectives of the project are very different. The results of the first objective are described in Sioen et al. (published in this issue). The results of the second objective are described in the present paper.

\section{Materials and methods}

\section{Market inventory}

A first step to achieve these objectives was to perform a market inventory in order to have an indication of the different PS-enriched food items and supplements as well as their PS concentration available on the Belgian market. For this purpose, different sale points were visited in October 2008 and all available foods enriched with PS and supplements containing PS were listed. In total, seventeen supermarkets of seven different chains (per chain supermarkets in two or three different provinces were visited), seven pharmacies and seven bio-shops, spread over different provinces in Flanders, were visited. During these visits, the brand and the details describing the type of the product as well as the amount of PS/portion were noted. Moreover, pictures of the products were taken in order to be used later in the questionnaire.

\section{Questionnaire}

The newly developed questionnaire comprised three parts. The first part of the questionnaire was a general introduction, which covered some general, personal and sociodemographic questions (date of birth, sex, length, weight, post code, number of family members, educational level, occupation and major activity during leisure time), as well as information on smoking and eating behaviour (following a specific diet or never consuming specific food items). Moreover, questions were included about the presence of specific health problems (diabetes, problems with cholesterol, weight or blood pressure) of themselves (only in the questionnaire for the adult group) or in close family members (grandparents, parents, brothers and/or sisters). For the adult group, a question concerning the use of cholesterol-lowering drugs was also added. The second part of the questionnaire was related to the use of PS supplements and included questions concerning their use and frequency of use as well as their brand name; the different available supplements were shown on a picture. The third part of the questionnaire was a semi-quantitative FFQ. In order to help the respondents, the FFQ contained a page showing pictures of the different foods that were included in the questionnaire. The first question of the FFQ asked if the respondents consumed these products or not. Furthermore, the questionnaire asked about the frequency and amount of consumption of foods enriched with PS during the previous month, to assess for each item in the list a mean consumption for that month. For margarine, an additional question was added to assess the amount of margarine used per slice of bread by means of three photos: spread thin; medium; thick.

A pilot test was organised with forty adults and ten parents of pre-school children to test the ease of use of the FFQ. Based on the results of the pilot test and the remarks received, the final questionnaire was developed.

\section{Population sample}

It was the objective to study two subgroups of the Belgian population: pre-school children $(2 \cdot 5-7$ years old) and adults (from 18 years onwards). For the present study, a newly developed questionnaire had to be completed by the participants (for adults) or a proxy (i.e. one of the parents) of the participants (for pre-school children). The questionnaire was very similar for both studied population groups and was developed only in Dutch. Therefore, only Dutch-speaking inhabitants of Belgium were included in the study, which means that the study was limited to Flanders (the northern, Dutch-speaking part of Belgium), including about $60 \%$ of the total Belgian population. The questionnaires were divided using a convenience sample strategy. The sample size was calculated based on the prevalence formula. A minimum of 400 persons was required to gain an idea of the prevalence of PS-enriched 
product users. Only one questionnaire per household was accepted. For the pre-school children group, the FFQ were distributed via schools in different provinces of Flanders. For the adult population, it was aimed to collect the FFQ from adult respondents of all age categories (from 18 years onwards) as well as from those living in all different provinces in Flanders.

The present study was conducted according to the guidelines laid down in the Declaration of Helsinki and all procedures involving human subjects were approved by the Ethical Committee of the Ghent University Hospital, Belgium. Written informed consent was obtained from all subjects (for pre-school children, one of the parents signed). The completed questionnaires were returned by postal mail or by direct contact with the field workers.

\section{Consumption scenarios}

Besides evaluating the intake of PS on the basis of consumption patterns, as recorded in the FFQ, it was also the objective to perform scenario analyses to assess the total PS intake when a large part of the population would consume foods enriched with PS (sum of the naturally occurring PS - published in Sioen et al. (this issue) and the PS added to novel foods). These analyses were only done for adults (from 15 years onwards), since they are the target group for these enriched products. For these consumption scenarios, the Belgian National Food Consumption Survey was used as a starting point. Within this survey, food consumption data were collected for a representative sample of the Belgian adult population from 15 years onwards. The food consumption data were collected during the year 2004 by means of a repeated (two times) non-consecutive $24 \mathrm{~h}$ recall. Complete data were available for 3083 adults, 1523 women and 1538 men (for twenty-two adults, the sex was unknown). More details about the methodology and the population characteristics of the Belgian food consumption survey have been described by De Vriese et al. ${ }^{(9)}$.

In Sioen et al. (published in this issue), these Belgian consumption survey data were used to assess the intake of naturally occurring PS. Within the present study, these data were used to calculate the intake of PS via novel foods in addition to the naturally occurring PS, assuming that two enriched products (margarine and yoghurt drinks) were commonly consumed by the whole population. The following two scenarios were considered:

(1) Assuming that all adults would replace their usual portion of margarine by an equal amount of PS-enriched margarine, containing $7 \cdot 5 \mathrm{~g}$ PS/ $100 \mathrm{~g}$.

(2) Besides the above scenario, all adults would consume with this enriched margarine one yoghurt drink per day containing $1.6 \mathrm{~g} \mathrm{PS} /$ portion.

No scenario was developed using cheese spread, due to a rather low consumption level of this product.

\section{Calculating the intake of plant sterols}

For the calculation and evaluation of the PS intake using the consumption data collected with the FFQ and the consumption scenarios, the concentration data of PS in different enriched foods and supplements that were listed during the market study were combined with the consumption data from both sources.

\section{Statistics}

Statistical analyses were performed using the SPSS for Windows software program (version 15.0; SPSS Institute, Chicago, IL, USA). Normality of continuous variables was tested using a Kolmogorov-Smirnov test $(P<0 \cdot 01)$. Spearman's correlations were used $(P<0.05)$ to investigate the correlations between two continuous variables, of which at least one was not normally distributed. The associations between two discontinuous variables were studied using a Pearson $\chi^{2}$ test $(P<0 \cdot 05)$. Significant differences between two groups were analysed using a $t$ test for independent samples $(P<0.05)$ for a normal continuous variable and a Mann-Whitney $U$ test was used $(P<0.05)$ for a non-normal continuous variable. Significant differences between more than two groups were analysed using a Kruskal-Wallis test $(P<0 \cdot 05)$.

\section{Results}

\section{Market inventory}

During the market inventory performed in October 2008, three different types of PS-enriched foods were found on the Belgian market: yoghurt drinks; spreads; a cheese spread. Moreover, four different food supplements containing PS were also found. Details about these foods and supplements are shown in Table 1.

\section{Population sample}

A total of 270 FFQ for pre-school children were distributed via schools, of which 151 (56\%) were returned after

Table 1. Available plant sterol-enriched foods and supplements containing plant sterols that were found on the Belgian market in October 2008

\begin{tabular}{lcccc}
\hline Type of food & Brand & $\begin{array}{c}\text { Amount of } \\
\text { plant sterols } \\
(\mathrm{g} / 100 \mathrm{~g})\end{array}$ & $\begin{array}{c}\text { Wt of a } \\
\text { portion }(\mathrm{g})\end{array}$ & $\begin{array}{c}\text { Amount of } \\
\text { plant sterols } \\
\text { (g/portion) }\end{array}$ \\
\hline Yoghurt drinks & 1 & 3 & 67.5 & 2 \\
& 2 & 1.6 & 100 & 1.6 \\
Spreads & 3 & 1.6 & 100 & 1.6 \\
& 1 & 7 & - & - \\
Cheese spread & 1 & 7.5 & - & - \\
Supplements & 1 & 1.7 & - & - \\
& 2 & 7.5 & - & - \\
& 2 & 45.45 & 0.44 & 0.2 \\
& 3 & 44.6 & 2 Capsules & 0.7 \\
& 4 & $0.8 \mathrm{~g} /$ tablet & 2 Capsules & 0.8 \\
& 4 & & & 1.6 \\
\hline
\end{tabular}


completion. However, of these 151 children, twelve were 2.5 years or younger, or older than 7 years or the age was unknown. A total of 139 FFQ were valid: sixty-eight from pre-school girls and seventy-one from pre-school boys. The age of the pre-school children was normally distributed, with a mean age of 4.8 (minimum 2.7 to maximum 6.7) years. For the adults, a total of 650 FFQ were distributed, of which 569 (88\%) FFQ were completed and returned: 308 (54.1\%) from women and 261 (45.9\%) from men. The age of the adult respondents was also normally distributed, with a mean age of 42.7 years and a range from 19 to 83 years. Of these, $80 \%$ were nonsmokers. The mean BMI was 24.8 (SD 4.0 ) $\mathrm{kg} / \mathrm{m}^{2}$ (2\% underweight, $56 \cdot 3 \%$ normal weight, $32 \cdot 1 \%$ overweight and $9.6 \%$ obese), based on the self-reported length and weight. Of the population sample, 50\% went to university college or university after finishing secondary school. Of the adult population, $67 \%$ were working full time and $17 \%$ were working part-time, 9\% were retired, 3\% were housewife/house husband, $2 \cdot 1 \%$ were unemployed and $1.5 \%$ were still studying. Of the total population, $9.6 \%$ used cholesterol-lowering drugs, $7 \cdot 7$ and $2 \cdot 1 \%$ suffered from high blood pressure or diabetes, respectively, and $8.5 \%$ indicated following a specific diet. Many different diets and combinations of diets were reported.

\section{Consumption of plant sterol-enriched foods and the plant sterol intake of Belgian pre-school children}

Of the 139 pre-school children who completed the questionnaire, four reported to follow a special diet: the first one did not consume egg-containing food items, the second did not consume food items containing cows' milk, the third followed a diet for diabetics combined with a low-energy diet and the last followed a low-fat and low-energy diet.

Within the group of 139 participating pre-school children, twenty-nine (20.9\%) consumed PS-enriched foods. Moreover, one child consumed a PS-containing food supplement. However, this child followed a diet for diabetics combined with a low-energy diet. The most consumed PS-enriched food item by these pre-school children was spread, followed by yoghurt drink. PS-enriched cheese spread was not consumed by pre-school children. No significant association was found between the consumption of PS-enriched foods and following a specific diet.

The prevalence of specific diseases within the family (grandparents, parents, brothers and/or sisters) of preschool children and the link with the consumption of PS-enriched foods were studied. No significant associations between the prevalence of specific diseases within family members and the consumption of PS-enriched foods were found. Fig. 1 illustrates the slight, but non-significant, differences between pre-school children not consuming PS-enriched foods ( $n$ 110) and those consuming PSenriched foods ( $n$ 29).

Among the twenty-nine pre-school children consuming PS-enriched foods, twenty-one completed enough quantitative details in the FFQ to make it possible to calculate PS intakes. The mean intake was 0.70 (SD 0.61) g/d, with a median intake of $0.53 \mathrm{~g} / \mathrm{d}$ and a minimum and maximum of 0.01 and $2 \cdot 10 \mathrm{~g} / \mathrm{d}$, respectively.

Consumption of plant sterol-enriched foods and the plant sterol intake of Belgian adults

Of the 569 participating adults, 162 (28.5\%) consumed PS-enriched food items. Further in the text, this group is

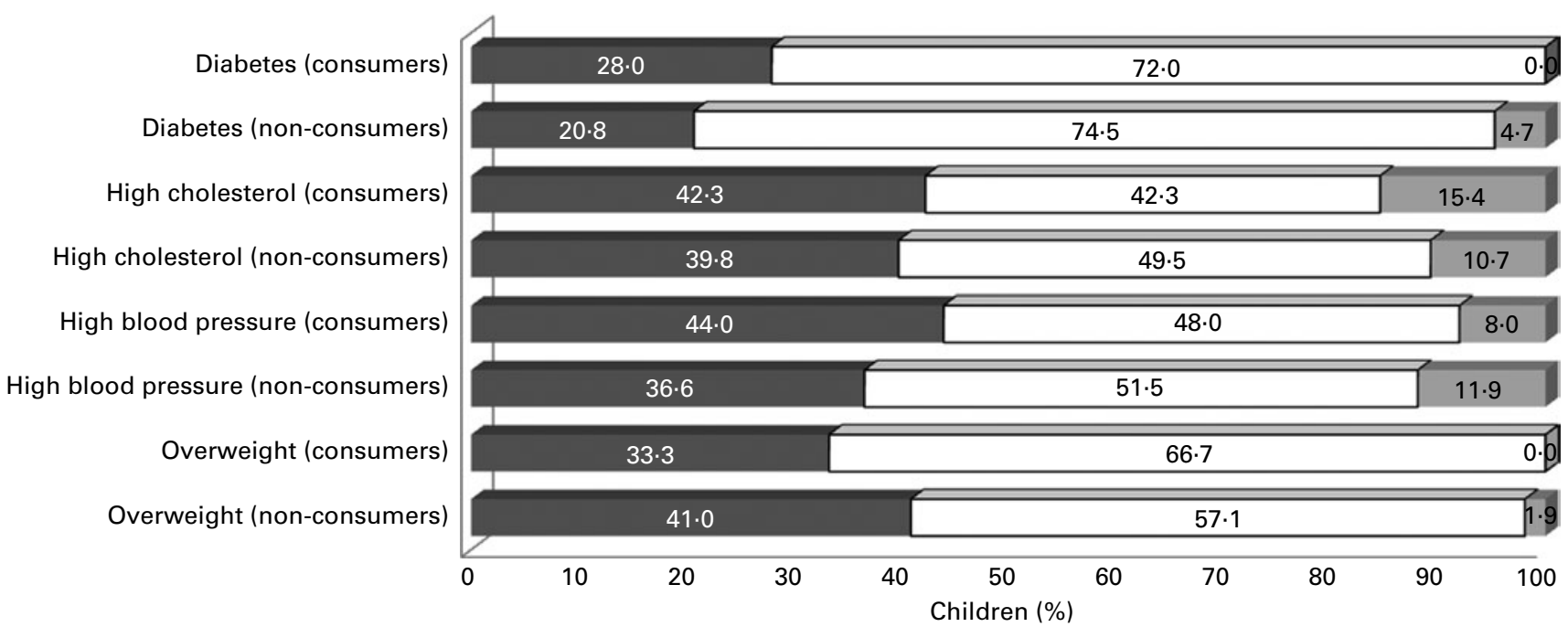

Fig. 1. Percentage of family members with a specific disease for the groups of children consuming and not consuming plant sterol-enriched food items. High cholesterol was defined as $>1900 \mathrm{mg} /$; high blood pressure was defined as $>140 / 90 \mathrm{mmHg}$; consumers: those children consuming plant sterol-enriched food items ( $n$ 29); non-consumers: those children not consuming plant sterol-enriched food items ( $n$ 110). The bars show the percentage of children: having family members with the disease $(\square)$ indicated on the $Y$-axis; not having family members with the disease $(\square)$ indicated on the $Y$-axis; not knowing whether they have family members with the disease $(\square)$ indicated on the $Y$-axis. 
Table 2. Relationship between the prevalence of high cholesterol level and the consumption of plant sterol-enriched foods in Flemish adults

\begin{tabular}{lcc}
\hline & \multicolumn{2}{c}{$\begin{array}{c}\text { Consuming plant } \\
\text { sterol-enriched foods }\end{array}$} \\
\cline { 2 - 3 } $\begin{array}{l}\text { High cholesterol level } \\
(>1900 \mathrm{mg} / \mathrm{l})\end{array}$ & Yes $(\%)$ & No $(\%)$ \\
\hline Yes $(n 110)$ & 49.1 & 50.9 \\
No $(n 315)$ & 22.5 & 77.5 \\
Not known $(n$ 122) & 25.4 & 74.6 \\
\hline
\end{tabular}

called 'consumers'. The age of consumers (on average $45 \cdot 7$ years old) was significantly higher $(P=0.032)$ compared with that of non-consumers (on average 41.5 years old). Also, BMI (not normally distributed within the population) was significantly higher $(P=0.004)$ for consumers (median BMI $24.8 \mathrm{~kg} / \mathrm{m}^{2}$ ) compared with non-consumers (median BMI $24.3 \mathrm{~kg} / \mathrm{m}^{2}$ ). Within the group of consumers, $40.7 \%$ were men and $59 \cdot 3 \%$ women. However, the $\chi^{2}$ test did not show a significant association between sex and the consumption of PS-enriched foods. In addition, no significant association was found between the consumption of PS-enriched foods and the highest degree of education. The $\chi^{2}$ test indicated that a significant association exists between the people following a diet and the consumption of PS-enriched foods. With the group of respondents following a diet, $58.3 \%$ reported using PS-enriched foods. For the respondents not following a diet, this was limited to $25 \cdot 6 \%$.

The relationship between the consumption of PSenriched foods and (1) the prevalence of a high cholesterol level $(>1900 \mathrm{mg} / \mathrm{l})$ (Table 2) as well as (2) the use of cholesterol-lowering drugs was investigated. A significant association was found between the use of PS-enriched food items and a high blood cholesterol level $(P<0.001)$ as well as with the use of cholesterol-lowering drugs $(P=0.002)$. The prevalence of high blood pressure $(>140 / 90 \mathrm{mmHg})$ or diabetes was not significantly associated with the consumption of PS-enriched foods. As for pre-school children, also the prevalence of specific diseases (overweight, diabetes, high cholesterol or high blood pressure) within the family ((grand)parents, brothers and/or sisters) was asked in the questionnaire. However, no significant associations between these parameters and the consumption of PS-enriched food items were found.

Only two persons $(0 \cdot 4 \%)$ reported using supplements containing PS, a man and a woman. Both of them reported having a high blood cholesterol level.

Of the 162 consumers, only 128 completed enough quantitative details in the FFQ to make it possible to calculate their intake of PS. Table 3 reports the PS intake of the total group of consumers as well as separately for men and women since the intake of both groups was significantly different. These results show that for both sexes, the 90th percentile exceeds the level of $3 \mathrm{~g} / \mathrm{d}$.

Spreads (65.4\%) contributed most to the overall PS intake of the consumers, followed by yoghurt drinks $(33.4 \%)$ and cheese spread (1.2\%). More than half of the consumers (56\%) consume PS-enriched spreads on a daily basis. In contrast, PS-enriched cheese spread is only consumed by six of the 128 consumers.

\section{Scenario studies}

The results of the scenario studies are shown in Table 3 . The results are shown separately for men and women since they were significantly different between both groups $(P<0 \cdot 001)$. Depending on the scenario and sex, $17-53 \%$ of the consumers have an intake above $3 \mathrm{~g} / \mathrm{d}$.

Table 3. Intake of plant sterols ( $\mathrm{g} / \mathrm{d}$ ) (1) via plant sterol-enriched food items for the adult study population (based on an FFQ), considering only those adults consuming the plant sterol-enriched foods, as well as (2) via non-enriched plus enriched foods for men and women for two different consumption scenarios using the consumption data of the Belgian National Food Consumption Survey (2004)

\begin{tabular}{|c|c|c|c|c|c|c|c|}
\hline & \multicolumn{7}{|c|}{ Plant sterol intake (g/d) } \\
\hline & \multicolumn{3}{|c|}{ Present intake via enriched food items (based on the FFQ) } & \multicolumn{2}{|c|}{$\operatorname{Men}^{*}(n$ 1538) } & \multicolumn{2}{|c|}{ Women $^{*}(n$ 1523) } \\
\hline & All consumers† ( $n$ 128) & Men† ( $n$ 52) & Woment $(n 76)$ & Scenario 1 & Scenario 2 & Scenario 1 & Scenario 2 \\
\hline Mean & 1.51 & 1.77 & 1.32 & 2.4 & 4.0 & 1.6 & 3.2 \\
\hline SD & 1.42 & 1.65 & 1.22 & $2 \cdot 8$ & $2 \cdot 8$ & $1 \cdot 7$ & 1.7 \\
\hline Minimum & 0.01 & 0.01 & 0.03 & 0.1 & 1.7 & 0.1 & 1.6 \\
\hline 50th Percentile & 1.00 & 1.60 & 1.00 & 1.6 & 3.2 & $1 \cdot 1$ & $2 \cdot 7$ \\
\hline 75th Percentile & $2 \cdot 35$ & $2 \cdot 84$ & 1.93 & 3.4 & $5 \cdot 0$ & $2 \cdot 3$ & 3.9 \\
\hline 90th Percentile & 3.46 & $4 \cdot 17$ & $3 \cdot 21$ & 5.5 & $7 \cdot 1$ & $3 \cdot 8$ & 5.4 \\
\hline 95th Percentile & $4 \cdot 20$ & 5.06 & 3.83 & $7 \cdot 1$ & $8 \cdot 7$ & $5 \cdot 2$ & $6 \cdot 8$ \\
\hline 97.5th Percentile & 5.07 & 6.51 & 4.55 & $9 \cdot 0$ & $10 \cdot 6$ & 6.5 & $8 \cdot 1$ \\
\hline Maximum & $6 \cdot 80$ & $6 \cdot 80$ & $5 \cdot 20$ & 41.6 & 43.2 & 11.3 & $12 \cdot 9$ \\
\hline Intake > $3 \mathrm{~g} / \mathrm{d}(\%)$ & 16 & 23 & 12 & 29 & 53 & 17 & 40 \\
\hline
\end{tabular}

* Based on the data of the Belgian National Food Consumption Survey (2004), scenario 1: assuming that all adults would replace their usual portion of margarine by an equal amount of plant sterol-enriched margarine, containing $7.5 \mathrm{~g}$ plant sterols $/ 100 \mathrm{~g}$; scenario 2 : assuming that all adults would replace their usual portion of margarine by an equal amount of plant sterol-enriched margarine, containing $7.5 \mathrm{~g}$ plant sterols $/ 100 \mathrm{~g}$, and would consume with this enriched margarine one yoghurt drink per day containing $1.6 \mathrm{~g}$ plant sterols/portion.

† Only those consuming plant sterol-enriched food items are included in the table. 


\section{Discussion}

\section{Market study}

The results of the market inventory indicated that the assortment of PS-enriched foods in Flanders is rather low (three different types of food products) compared with the list of the European regulation indicating the types of foods that may be enriched with PS. Unfortunately, an official register indicating PS-enriched foods and supplements available on the market was accessible but not up to date, since the market of these products changes very rapidly. As the market of novel foods is very dynamic, with many changes according to customer demand, the current list has just a temporal value. When compared with what is stated in the European Food Safety Authority report ${ }^{(2)}$, it was found that, at the end of 2007, PS-enriched yoghurt, milk and soya drink were available in Belgium. However, during the present study, these products were not found on the market anymore. For spreads, it is remarkable that one of the four brands has a much lower PS concentration than the others. Variability within supermarket stores of the same brand was found. For supplements, the concentration per recommended portion, as stated on the package, is rather low when compared with the fact that a consumption of $1-3 \mathrm{~g} / \mathrm{d}$ is found as an optimal amount to decrease LDL-cholesterol.

\section{FFQ and population sample}

A higher percentage of completed FFQ was found in the adult group compared with pre-school children. This can be explained by the fact that adults were first asked by the fieldworkers whether they were willing to participate before they received an FFQ, while in the group of preschool children, the FFQ were distributed via schools.

An important limitation of the present study was the fact that it was not possible within the project to work with a random selection, representative of the Flemish or Belgian population for both subgroups of the population. The adult population that completed the FFQ seemed to be more highly educated than the overall Flemish adult population (about 50\% went to university college or university) and the majority of the respondents were working full time. Assuming that a higher educational level as well as a higher number of working hours per week are related to a higher income, and knowing that PS-enriched foods are sold for a higher price compared with non-enriched alternatives, this could have an influence on the final results of the present study, i.e. the reported consumption of PS-enriched foods would be lower for an at-random population sample. Moreover, the used FFQ was tested for its ease of use, but not validated using, for example, a dietary record for comparison. This limitation must be kept in mind when interpreting the results.
Consumption of plant sterol-enriched foods and the plant sterol intake of Belgian pre-school children

The results of the present study showed that $21 \%$ of the participating pre-school children consume PS-enriched foods, while they do not belong to the target group of these products (i.e. people who need to lower their blood cholesterol level). In contrast, the European legislation indicates that PS-enriched food products may not be nutritionally appropriate for children under the age of 5 years. Also, in a food consumption database of Flemish pre-school children, dating back from 2002, it was found that, by that time, $3 \%$ of the pre-school children consumed PS spreads during at least one of the $3 \mathrm{~d}$ of the consumption survey (for more information, see Sioen et al. (published in this issue)). And possibly, this percentage is even an underestimation, since often the brand name of the spread was not indicated, resulting in the assumption that these were non-enriched spreads.

None of the children in the present study reaches an intake exceeding $3 \mathrm{~g} / \mathrm{d}$, the level that should be avoided. However, this is a maximum level that is defined for adults. When considering the difference in body weight between adults and pre-school children, this should probably be lower for pre-school children. Moreover, it can be assumed that the physiological and toxicological effects of PS in children are different compared with those in adults. Nevertheless, a 3.5-year-old child participating in the present study had an intake above $2 \mathrm{~g} / \mathrm{d}$, due to daily consumption of a PS-enriched spread.

\section{Consumption of plant sterol-enriched foods and the plant sterol intake of Belgian adults}

This project showed that $28.5 \%$ of the participating Flemish adults consume PS-enriched food products. Of the consumers who have an idea of their blood cholesterol level (125 of the 162 consumers), $57 \%$ did not suffer from high blood cholesterol level, which indicates that these products are also used by adults not belonging to the target group. A possible explanation can be that people use it as a format of primary prevention. Nevertheless, no significant association was found with the prevalence of high blood cholesterol within family members. Moreover, other dietary strategies such as lowering the intake of cholesterol and SFA are more advisable in primary prevention of a high cholesterol level. The consumption of PS-enriched foods is linked with higher age, higher BMI, following a specific diet and using cholesterol-lowering drugs. No significant associations were found with sex or the highest degree of education, nor with suffering from high blood pressure or diabetes.

The adults' mean PS intake due to the consumption of enriched products was 1.51 (SD 1.42) g/d. However, within the group of consumers, $50 \%$ had a PS intake lower than or equal to $1 \mathrm{~g} / \mathrm{d}$, which can be considered as 
a suboptimal dose to reach the predicted LDL-cholesterollowering effect ${ }^{(6,10)}$. In contrast, $16 \cdot 4 \%$ of the consumers had a PS intake above $3 \mathrm{~g} / \mathrm{d}$, even $7.8 \%$ had an intake above $4 \mathrm{~g} / \mathrm{d}$. The consumers who exceed the intake of $3 \mathrm{~g} / \mathrm{d}$ use all but one PS-enriched spread. Some of them combine it with other PS-enriched food products.

The results of the Flemish adults can be compared with the results of an Irish study ${ }^{(8)}$, focusing on the consumers of PS-enriched food products. The Irish study collected data by means of an interview-assisted questionnaire in order to calculate the PS intake and to characterise the consumer group. Since the methodology between the two studies is different, the value of comparison is limited. In the Irish study, $61 \%$ of the consumers had a high blood cholesterol level and $22 \%$ used cholesterol-lowering drugs. In total, $23 \%$ of the Irish consumers had an intake above $3 \mathrm{~g} / \mathrm{d}$ (mean intake 2.45 (SD 1.46) g/d), compared with $16 \%$ of the Flemish consumers of PS-enriched food items (mean intake 1.51 (SD 1.42) g/d). Similar to Flanders, Irish men had higher intakes (mean intake $2 \cdot 71$ $(\mathrm{SD} 1.50) \mathrm{g} / \mathrm{d}$ ) compared with Irish women (mean intake $2 \cdot 29(\mathrm{SD} 1 \cdot 41) \mathrm{g} / \mathrm{d})$.

\section{Scenario studies}

The first consumption scenario (replacing all spreads by PS-enriched spreads) was a way to assess the effect of the reformulation of food items, since in this scenario, it is assumed that consumers did not change their consumption pattern, only the composition of a food itemis changed. The reported PS consumption includes naturally occurring PS (as calculated in Sioen et al. (published in this issue)) as well as PS added to novel foods. This scenario leads to a median PS intake of 1.6 and $1.1 \mathrm{~g} / \mathrm{d}$ for men and women, respectively, with $29 \%$ of men and $17 \%$ of women exceeding the level of $3 \mathrm{~g} / \mathrm{d}$. For the second scenario, the median PS intake would be 3.2 and $2.7 \mathrm{~g} / \mathrm{d}$ for men and women, respectively, with $53 \%$ of men and $40 \%$ of women exceeding the level of $3 \mathrm{~g} / \mathrm{d}$.

Also, other scientific papers report the results of scenario analyses assessing the intake of PS when PS-enriched foods would be consumed on a large scale. The results of these studies are used to compare the results of the scenario studies presented in the present study. On the basis of a Dutch cross-sectional study, the intake of PS was calculated, assuming a replacement of all spreads, cheese and yoghurt by PS-enriched alternatives ${ }^{(7)}$. This resulted in a median PS intake of 5.5 and $4.6 \mathrm{~g} / \mathrm{d}$ for men and women, respectively. In the scenario where only spreads were replaced by PS-enriched spreads, they found a median intake of $2.4 \mathrm{~g} / \mathrm{d}(3.6$ and $4.9 \mathrm{~g} / \mathrm{d}$ for the 75 th and 90 th percentile, respectively) for the total population (the results were not reported separately for both sexes). These results are quite similar compared with the results found in the first scenario for the Belgian men. In this Dutch study, the calculated intakes of PS are compared with a cut-off level of $8.6 \mathrm{~g} / \mathrm{d}$, which is the level beyond which no clinical effects of the long-term intake of PS have been studied properly $^{(7)}$. When comparing the results of the present study with the cut-off level of $8.6 \mathrm{~g} / \mathrm{d}$, none of the consumers exceeds the level on the basis of their present consumption pattern. However, it is found that, for scenario 2 (consumption of PS-enriched spreads and yoghurt drinks), $5 \%$ of men and $2 \%$ of women would exceed this cut-off.

Also, a German study investigated the effect of a largescale use of PS-enriched food products ${ }^{(8)}$. They considered different scenarios in which $0 \cdot 3-2 \mathrm{~g}$ PS would be added to usual daily portions of ten different food items (among others spreads, milk, yoghurt, cheese, salami and bread). Depending on the number of food items being enriched at the same time, they found a mean intake of PS from 3 to $6 \mathrm{~g} / \mathrm{d}$, with a maximum of $13 \mathrm{~g} / \mathrm{d}$.

\section{Conclusion}

The results of the present study - unfortunately not based on a representative sample of the population - showed that PS-enriched food products are consumed by $21 \%$ of the Flemish pre-school children and $28.5 \%$ of the Flemish adults. Of these adults, $57 \%$ do not know if they suffer from an increased blood cholesterol level. These results indicate that the price premium afforded to PS-enriched food products is not a natural barrier to avoid excessive intakes by the non-target group in Flanders, as was suggested in the European Food Safety Authority report ${ }^{(2)}$. Moreover, for those adults using PS-enriched products, only $34 \%$ had a PS intake between 1 and $3 \mathrm{~g} / \mathrm{d}$, which is advisable to reach the desirable effect. Scenario studies assessed the intake when all Belgian adults would consume PS-enriched margarines without (scenario 1) or with (scenario 2) a daily consumption of a PS-enriched yoghurt drink. This resulted in an intake above $3 \mathrm{~g} / \mathrm{d}$ in $17 \%$ (women) and 29\% (men) for scenario 1 and $40 \%$ (women) and 53\% (men) for scenario 2. The results of the present study show that, in the future, efficient communication tools are needed to inform consumers better about the target group of PS-enriched products, the advised dose per day and other dietary strategies to lower blood cholesterol level.

\section{Acknowledgements}

The present study (project RT-07/3 PHYTOST) as well as the Belgian National Consumption Survey (2004) was funded by the Belgian Federal Public Service of Health, Food Chain Safety and Environment. C. M., J. V. C. and S. D. H. prepared the project proposal and set up the study design. C. M. organised the fieldwork. C. M. and I. S. coordinated the fieldwork. I. S. analysed the data, wrote the project report and the manuscript. I. H. was closely involved in all steps of the Belgian National 
Consumption Survey. All authors read the manuscript and provided detailed comments to improve the manuscript. The authors acknowledge all the people who completed the questionnaire. Moreover, we thank the four students, Evelien Eeckhout, Silke Souffriau, Natalie Van den Briel and Margje Vereycken, for their help in the fieldwork in the framework of their bachelor thesis. Finally, the dietitians, Mia Bellemans, Mieke De Maeyer, Melissa De Neve and Anja Polet, of the unit Nutrition and Food Safety, Department of Public Health, Ghent University, are thanked for their contribution to the project. C. M. is affiliated with the Department of Public Health, Ghent University as a voluntary post-doctoral researcher. $\mathrm{He}$ is currently working for the not-for-profit organisation, International Life Science Institute - Europe Branch, located in Brussels, Belgium.

\section{References}

1. Ostlund RE (2002) Phytosterols in human nutrition. Annu Rev Nutr 22, 533-549.

2. EFSA (2008) Consumption of foods and beverages with added plant sterols in the European Union. EFSA J 133, 1-21.
3. Katan MB, Grundy SM, Jones P, et al. (2003) Efficacy and safety of plant stanols and sterols in the management of blood cholesterol levels. Mayo Clin Proc 78, 965-978.

4. Caswell H, Denny A \& Lunn J (2008) Plant sterol and stanol esters. Nutr Bull 33, 368-373.

5. Van Amstersdam JGC, Opperhuizen A \& Jansen EHJM (2005) Accumulation of phytosterols in food. Evaluation of the adverse effects following the intake of high dose of phytosterols. RIVM report 340240001/2005.

6. Hearty A, Duffy E, Joyce J, et al. (2009) Phytosterol-enriched products on the Irish market: examination of intake and consumption patterns. Public Health Nutr 12, 51-58.

7. de Jong N, Pijpers L, Bleeker JK, et al. (2004) Potential intake of phytosterols/-stanols: results of a simulation study. Eur J Clin Nutr 58, 907-919.

8. Kuhlmann K, Lindtner O, Bauch A, et al. (2005) Simulation of prospective phytosterol intake in Germany by novel functional foods. BrJ Nutr 93, 377-385.

9. De Vriese S, De Backer G, De Henauw S, et al. (2005) The Belgian food consumption survey: aims, design and methods. Arch Public Health 63, 1-16.

10. Scientific Committee on Food (2002) General view of the Scientific Committee on Food on the long-term effects of the intake of elevated levels of phytosterols from multiple dietary sources, with particular attention to the effects of beta-carotene (published on 26 September 2002). European Commission SCF/CS/NF/DOS/20 ADD1. 